\title{
Publisher Correction: Anti-CRISPR proteins encoded by archaeal lytic viruses inhibit subtype I-D immunity
}

Fei He, Yuvaraj Bhoobalan-Chitty (D), Lan B. Van, Anders L. Kjeldsen, Matteo Dedola, Kira S. Makarova, Eugene V. Koonin (D,

Ditlev E. Brodersen (iD) and Xu Peng (D)

Correction to: Nature Microbiology https://doi.org/10.1038/s41564-018-0120-z, published online 5 March 2018.

In the original version of this Article, molecular weight markers in Figs 1c, 2c, d and 4d were displaced during the production process, so that they were not correctly aligned with the corresponding bands. In addition, in Fig. 4c, molecular masses given for three different elution volumes were displaced so that they appeared to the left of the correct positions. These errors have now been corrected.

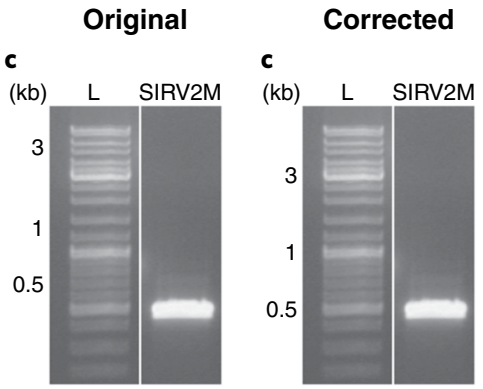

Fig. 1c | Original and corrected.

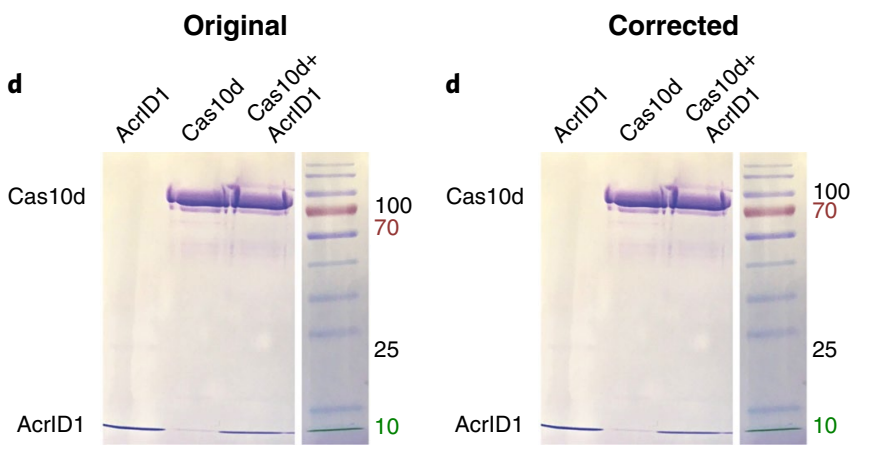

Fig. 4d | Original and corrected.

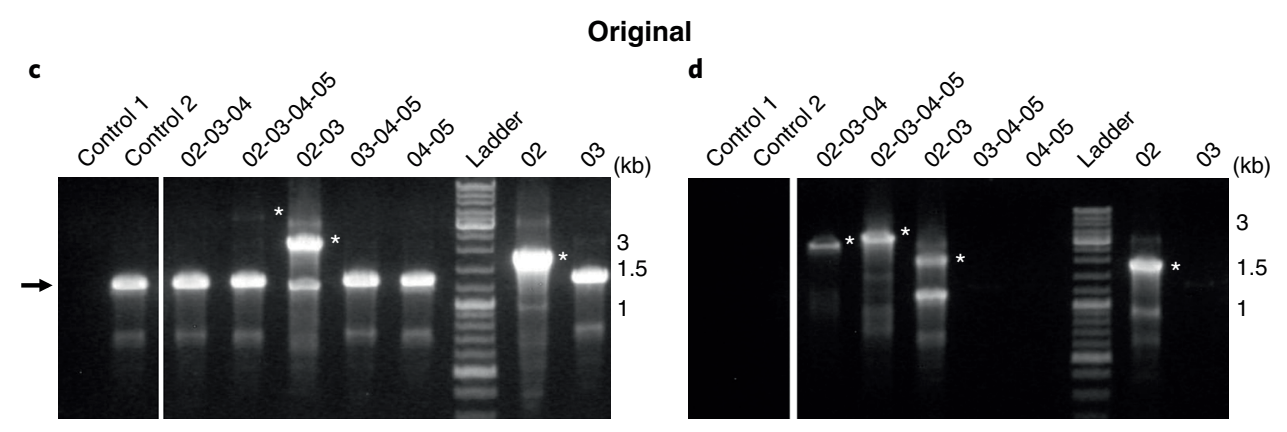

Corrected
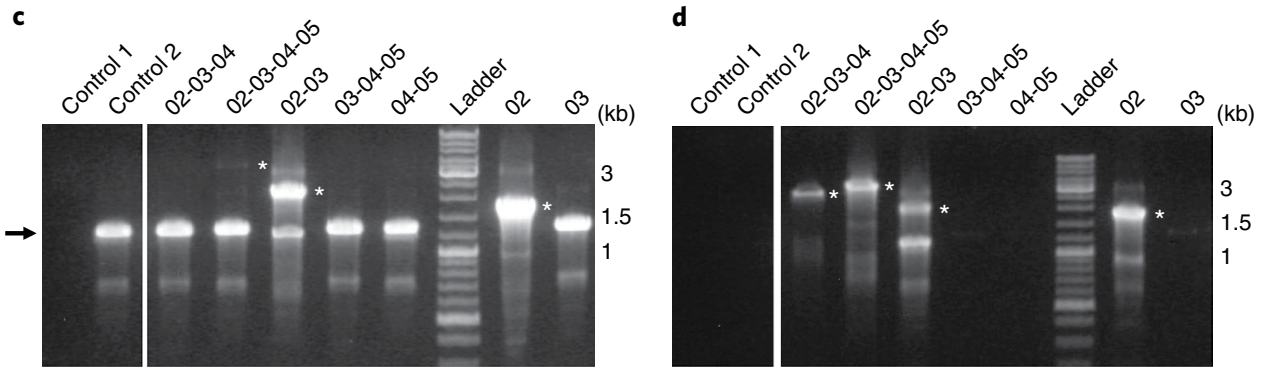

Fig. 2c,d | Original and corrected. 